\title{
BMJ Open Severity and management of postabortion complications among women in Zimbabwe, 2016: a cross- sectional study
}

\author{
Mugove Gerald Madziyire, ${ }^{1}$ Chelsea B Polis, ${ }^{2}$ Taylor Riley, ${ }^{2}$ Elizabeth A Sully, ${ }^{2}$ \\ Onikepe Owolabi, ${ }^{2}$ Tsungai Chipato ${ }^{1}$
}

To cite: Madziyire MG, Polis CB, Riley $\mathrm{T}$, et al. Severity and management of postabortion complications among women in Zimbabwe, 2016: a crosssectional study. BMJ Open 2018;8:e019658. doi:10.1136/ bmjopen-2017-019658

- Prepublication history and additional material for this paper are available online. To view these files, please visit the journal online (http://dx.doi org/10.1136/bmjopen-2017019658).

Received 19 September 2017 Revised 21 November 2017 Accepted 4 January 2018

\section{Check for updates}

${ }^{1}$ Department of Obstetrics and Gynaecology, University of Zimbabwe College of Health Sciences, Harare, Zimbabwe ${ }^{2}$ Guttmacher Institute, Manhattan, New York, USA

Correspondence to Dr Mugove Gerald Madziyire; gynaemadzi@y7mail.com

\section{ABSTRACT}

Objectives Abortion complications cause significant morbidity and mortality. We aimed to assess the severity and factors associated with abortion complications (induced or spontaneous), and the management of postabortion care (PAC) in Zimbabwe. Design Prospective, facility-based 28 day survey among women seeking PAC and their providers. Setting 127 facilities in Zimbabwe with the capacity to provide PAC, including all central and provincial hospitals, and a sample of primary health centres (30\%), district/general/mission hospitals $(52 \%)$, private (77\%) and non-governmental organisation (NG0) (68\%) facilities.

Participants 1002 women presenting with abortion complications during the study period.

Main outcome measures Severity of abortion complications and associated factors, delays in care seeking, and clinical management of complications. Results Overall, $59 \%$ of women had complications classified as mild, $19 \%$ as moderate, $19 \%$ as severe, $3 \%$ as near miss and $0.2 \%$ died. A median of 47 hours elapsed between experiencing complication and receiving treatment; many delays were due to a lack of finances. Women who were rural, younger, not in union, less educated, at later gestational ages or who had more children were significantly more likely to have higher severity complications. Most women were treated by doctors ( $91 \%)$. The main management procedure used was dilatation and curettage/dilatation and evacuation (75\%), while $12 \%$ had manual vacuum aspiration (MVA) or electrical vacuum aspiration and $11 \%$ were managed with misoprostol. At discharge, providers reported that $43 \%$ of women received modern contraception.

Conclusion Zimbabwean women experience considerable abortion-related morbidity, particularly young, rural or less educated women. Abortion-related morbidity and concomitant mortality could be reduced in Zimbabwe by liberalising the abortion law, providing PAC in primary health centres, and training nurses to use medical evacuation with misoprostol and MVA. Regular in-service training on PAC guidelines with follow-up audits are needed to ensure compliance and availability of equipment, supplies and trained staff.
Strengths and limitations of this study

- This nationally representative study covered all provinces in Zimbabwe, included all central and provincial hospitals which have a high postabortion care (PAC) caseload, and avoided concerns encountered in retrospective studies assessing abortion-related morbidity due to missing patient records.

- Our revised morbidity criteria reduce potential overestimation of severity by removing unreliable stand-alone criteria such as fever and tachycardia.

- We were unable to distinguish between induced and spontaneous abortions.

- Information on women with mild complications that resolved spontaneously, severe complications leading to death outside the facility, or any other case of PAC occurring outside of a facility were not captured.

\section{INTRODUCTION}

Unsafe abortion remains an important cause of maternal morbidity and mortality. ${ }^{1}$ Globally, between 2010 and 2014, about 25.1 million unsafe abortions occurred annually, largely $(97 \%)$ in low/middle-income countries. ${ }^{2}$ Nearly 22000 women died due to unsafe abortions in $2014,{ }^{3}$ and many more suffered serious injuries. Approximately $12 \%$ of maternal deaths globally are attributed to abortion (this includes ectopic pregnancies). ${ }^{4}$ Of the estimated 6.2 million unsafe abortions in Africa yearly, one-third occur in Eastern Africa, where Zimbabwe is located. ${ }^{2}$

In Zimbabwe, abortion is highly restricted and permitted only in cases of rape, incest, when the mother's life is at risk, or when the child may be born with serious mental or physical disabilities. ${ }^{5}$ Restrictive abortion laws are not associated with lower levels of abortion, ${ }^{6}$ but are associated with increased abortion-related morbidity and mortality. Zimbabwe failed to meet the 2015 Millennium 
Development Goal of reducing the maternal mortality ratio (MMR) by $75 \%$. In fact, while most countries experienced declines in maternal mortality, ${ }^{7}$ Zimbabwe's MMR increased from 450 per 100000 live births in $1990^{8}$ to 651 in $2015 .^{9}$ Estimates of maternal mortality attributable to abortion complications in Zimbabwe range from $6 \%$ to $23 \%$, although these estimates come from older studies with methodological limitations. ${ }^{1011}$

One approach to reducing abortion-related morbidity and mortality involves improving access to and quality of postabortion care (PAC); such efforts are ongoing in Zimbabwe. National guidelines for comprehensive PAC have been in place since 2001, and were updated in $2014 .^{12}$ These guidelines emphasise medical management of abortion complications with misoprostol, preference for manual vacuum aspiration (MVA) over dilatation and curettage (D\&C) for first trimester abortions, and provision of family planning services. ${ }^{12}$ However, in many settings, health practitioners do not always adopt or maintain use of efficacious, cost-effective innovations. ${ }^{13}$ Furthermore, during the past decade, Zimbabwe has undergone economic stagnation, ${ }^{14}$ potentially affecting health delivery systems, including PAC provision. Access to PAC may also be limited due to stigma, costs and other factors leading to delays in seeking care. ${ }^{15}$ No recent studies have examined postabortion complications in Zimbabwe. We conducted a national survey to assess the severity and management of postabortion complications, and to understand the factors associated with experiencing severe complications.

\section{METHODS}

We employed the Prospective Morbidity Methodology to collect information from PAC patients and their providers on complications from spontaneous and induced abortions treated in a health facility. This methodology was developed by WHO,${ }^{16}$ modified by Ipas ${ }^{17-21}$ and further refined by the Guttmacher Institute. ${ }^{22} 23$ We conducted this study in conjunction with a project estimating the incidence of induced abortion in Zimbabwe; those methods and results are provided elsewhere. ${ }^{24}$

\section{Data collection}

We conducted a facility-based, prospective survey for 28 days between August and September 2016 among women seeking PAC in Zimbabwe. We compiled a comprehensive list of the 245 facilities in Zimbabwe with the capacity to provide $\mathrm{PAC}^{24}$ (online supplementary table 1 ). We sampled facilities stratified by province and level, selecting all central $(n=5)$ and provincial $(n=8)$ hospitals, and identified a random sample of primary health centres $(30 \%)$, district/general/mission hospitals (52\%), private facilities $(77 \%)$ and NGO facilities (68\%; includes for-profit and not-for-profit facilities). Overall, we selected 133 facilities, of which 127 participated, resulting in a facility-level response rate of $95 \%$.
All women presenting with incomplete, inevitable, missed, complete or septic abortion during the study period were eligible for inclusion. We could not distinguish between induced or spontaneous abortions, which are often clinically indistinguishable to providers. Furthermore, women often under-report induced abortion due to stigma and fear of being reported to police; for example, 52\% of adolescent girls in Zimbabwe believe an unmarried woman seeking treatment in public facilities for postabortion complications will be reported to police. ${ }^{25}$ Since information reported by both women and providers may not reliably distinguish between induced and spontaneous abortions, results presented are for all PAC patients. We note that complications from induced abortions may be more severe than those from spontaneous abortions. ${ }^{26}$

Data were collected by one to two nurses in each facility who coordinated with facility PAC providers to track participants. Once the patient was treated and in a stable condition, the interviewer sought informed consent to conduct a face-to-face interview with her, as well as her consent to separately interview her healthcare provider about her case and review her medical file. All women seeking PAC in each facility were recorded in a tracking form, including women who were near misses and too ill to be interviewed and women who died before being interviewed. Among an unweighted total of 1018 eligible patients, 1002 were interviewed (98\%) and 986 consented for the provider interview (97\%) (online supplementary table 1). Study staff and Ministry of Health and Child Care provincial Reproductive Health Officers supervised data collection.

\section{Key variables}

\section{Outcome: postabortion complication severity}

We developed a five-level classification system of postabortion complication severity: mild, moderate, severe, near miss or death (box 1). These classifications were adapted from the original criteria proposed by Rees $e t a l$ which has been used in prior studies. ${ }^{180-22} 27$ We expanded our criteria to include the adapted WHO near-miss criteria ${ }^{28}$ for a low/ middle-income country context. ${ }^{29}{ }^{30}$ Near-miss cases have similar morbidities to cases that result in death but occur more frequently and survive because of the treatment they receive. They are therefore useful to assess quality of care for abortion-related emergencies and to understand circumstances around abortion-related deaths. ${ }^{31}$ These modifications aimed to improve the objectivity of the clinical criteria and overall reliability and content validity. For the severe category and above, we shifted away from standalone clinical signs (eg, fever and tachycardia) which may lead to overestimation of severity. Furthermore, we removed 'evidence of a foreign body' as a sole criterion for severe complications, as this may not indicate severe morbidity, and is based on subjective provider reports, which may be affected by provider stigma and restrictive abortion laws. Severity classifications were mutually exclusive, and women were classified into the highest level of severity for which they met the criteria. 


\section{Box 1 Criteria for classification of abortion-related morbidity}

Mild morbidity (requires all criteria)

- Temperature $35.1^{\circ} \mathrm{C}-38.9^{\circ} \mathrm{C}$ with no clinical signs of infection*

- No system or organ failure $\dagger$

- Systolic blood pressure $\geq 90 \mathrm{~mm} \mathrm{Hg}$

- Haemorrhage not requiring any transfusion

Moderate morbidity (requires $\geq 1$ criterion)

- Temperature $37.3^{\circ} \mathrm{C}-38.9^{\circ} \mathrm{C}$

- Clinical signs of infection*

- No organ or system failure†

- No sign of shockł

- Haemorrhage not requiring any transfusion

Severe morbidity (requires $\geq 1$ criterion)

- Temperature $\geq 39^{\circ} \mathrm{C}$ or $\leq 35^{\circ} \mathrm{C}$ and a clinical sign of infection§

- Sepsis/septicaemia with no signs of septic shock $\neq$

- Pelvic abscess or pelvic peritonitis with no signs of shock

- Clinical anaemia without haemorrhagic shock

- Uterine perforation without laparotomy or repair of perforated uterus, repair of gut perforation, hysterectomy

Near-miss (requires $\geq 1$ criterion)

- Haemorrhagic shock

> Septic shock $\neq$

- Generalised peritonitis

- Uterine perforation with laparotomy or repair of uterine perforation, repair of gut perforation or hysterectomy

Organ/system failure $†$

- Massive blood transfusionๆ

Death

- Loss of the life of a woman as a result of an abortion complication

Severity classifications were mutually exclusive. Due to data quality concerns with temperature recordings not aligning with expected clinical symptoms, we expanded the definition of normal temperature $\left(35.1^{\circ} \mathrm{C}-37.2^{\circ} \mathrm{C}\right)$ to more accurately capture very low temperatures, which are a sign of shock or infection. To be classified as having severe morbidity, a patient had to have a very low or very high temperature along with a clinical sign of infection, or any of the other criteria. This prevents patients with only recorded low temperature and no other symptoms from being inaccurately captured as a severe case. A normal temperature (ie, a mild morbidity category) was imputed for three cases with missing temperature and who also had no other clinical symptoms. There were four other cases that did not fall into any of the categories based on their clinical criteria. Three cases had low temperature $\left(<35^{\circ} \mathrm{C}\right)$ but no other signs of complications so the medical doctors on the study team determined these cases should be classified as mild morbidity. One case had tachycardia, stayed in the hospital for more than 24 hours and was given oral and IV antibiotics but had normal temperature and no other complications. The medical doctors on the team determined this case should be classified as moderate morbidity.

${ }^{*}$ Clinical signs of infection can include: fever $>37.3^{\circ} \mathrm{C}$ and abdominal/uterine tenderness with or without foul smelling vaginal discharge or pelvic abscess or pelvic peritonitis.

†System or organ failure can include: liver failure or renal failure or cardiac arrest/failure or respiratory distress syndrome or coma or disseminated intravascular coagulopathy.

¥Shock can manifest as: a persistent systolic blood pressure $\leq 80 \mathrm{~mm} \mathrm{Hg}$ alone or a persistent systolic blood pressure $\leq 90 \mathrm{~mm} \mathrm{Hg}$ with a pulse rate at least $120 \mathrm{bpm}$, and restlessness, reduced consciousness, cold clammy peripheries, requiring administration of IV fluids.

$\S$ For severe, the clinical sign of infection also includes sepsis or pelvic abscess or pelvic peritonitis, or uterine perforation.

१Massive blood transfusion refers to replacement of $\geq 2$ units of blood.

IV, intravenous.

\section{Covariates}

We collected information on sociodemographic and reproductive health-related characteristics and about various delays that may occur in obtaining care for postabortion complications, including reasons for those delays. Furthermore, we inquired about amount of income lost to the respondent or her household as a result of experiencing health problems (excluding the actual costs of treatment or transportation). Variables that merit additional explanation are described below.

\section{Trimester}

This was measured using clinician-estimated gestational age in weeks (first trimester: 1-12 weeks, second trimester: 13-27 weeks, third trimester: 28 weeks term). Under $5 \%$ of unweighted cases $(47 / 1002)$ were missing the clinician's estimate; for 36 we used women's self-reported gestational age, and the remaining 11 were missing.

\section{Wealth}

We constructed wealth indicators among our participants comparable to the national-level wealth quintiles using data from the 2015 Zimbabwe Demographic and Health Survey (DHS). ${ }^{9}$ We performed principal components analysis using information on assets (eg, car, bicycle, refrigerator, etc) and household characteristics (type of water source, toilet facility and roofing material) available in both the DHS and our questionnaire. We generated factor weights for each asset or characteristic, ${ }^{32}$ and used them to calculate individual wealth scores for each person in the DHS. We split those wealth scores 
into relative quintiles (poorest, poor, medium, wealthy, wealthiest) and noted the cut points for each quintile. Next, we applied those factor weights to variables in our survey data, constructed individual wealth scores and classified women into a quintile, using the DHS-derived cut points. ${ }^{9}$ We conducted this procedure separately for urban women and for rural women, since wealth indicators vary substantially by place of residence. Therefore, our final wealth indicator defines each wealth quintile differently based on urban/rural residence.

\section{Analysis}

We performed all analyses in Stata V.14.1. We conducted descriptive analyses to determine frequencies for categorical variables and calculated medians (or means) for continuous variables. We applied facility-level weights and calculated standard errors taking into account the complex sample design, including adjusting for stratification by province and facility level, clustering of women at the facility level, and facility non-response, and applying a finite population correction.

To examine factors associated with increasing severity of postabortion complications, we conducted ordinal regression, using a three-level severity variable (collapsed from the original five levels to avoid estimation problems due to small cell sizes). The levels were defined as: (1) mild complications, (2) moderate complications or (3) severe complications including near miss or death. We assessed variables demonstrated in prior analyses to be significantly associated with abortion severity (urban/ rural residence, marital status, educational level, pregnancy duration), ${ }^{27}$ and variables we hypothesised may be associated with severity (age, parity, facility level, wealth status, delays in access to care). Variables with a $\mathrm{P} \leq 0.25$ in bivariate analysis were considered for inclusion in a multivariate model. We assessed for collinearity and confirmed that our model did not violate the proportional odds assumption, and used a planned backward block stepwise regression approach. ${ }^{33}$

\section{RESULTS}

Women presenting with postabortion complications in our study ranged from 15 to 47 years old, with adolescents (ages 15-19) accounting for 12\% of PAC patients (online supplementary table 2$)$. Most were in union $(80 \%)$, had partial or complete secondary schooling $(71 \%)$ and were not formally employed $(63 \%)$. More rural women were adolescents compared with urban women $(17 \%$ rural vs $8 \%$ urban), less likely to have attended university (19\% urban vs $6 \%$ rural) and more likely to not be formally employed ( $77 \%$ rural vs $54 \%$ urban). Women in our study were wealthier when compared against the national distribution of wealth, with $37 \%$ classified in the 'wealthiest' quintile, according to place of residence. This was more evident among rural women; nearly half $(47 \%)$ of rural women were classified in the "wealthiest' quintile. Women reported that most pregnancies resulting in complications for which they were seeking care were wanted at the time of pregnancy $(70 \%)$, while $15 \%$ were wanted later and $15 \%$ were not wanted. Most women $(65 \%)$ were in the first trimester of pregnancy. The largest proportion of patients $(40 \%)$ were managed in district, general or mission hospitals $(24 \%$ urban vs $65 \%$ rural); an additional $29 \%$ were served in central hospitals.

Out of a weighted total of 1282 women, $59 \%$ had mild morbidity, $19 \%$ had moderate morbidity, $19 \%$ had severe morbidity, 3\% were classified as near miss and $0.2 \%$ participated in the survey but later died (online supplementary figure 1). There were two additional deaths and 12 near misses recorded in facility tracking forms. Since no data could be collected on these patients for verification, these near misses and deaths are not included in this severity distribution.

Women reported that it took a median time of 47 hours from the time of experiencing complications until receiving complete treatment (table 1). This includes all health-seeking delays: realising care was needed, deciding to seek care, arriving at a facility, being attended to and completing treatment. The median self-reported delay in realising care was needed was 8 hours (range: <1-2688 hours). The median delay in deciding to seek care after realising it was needed was 2 hours (range: <1-1008). The most common reasons for this delay included lack of money (41\%), partner or family member making the decision (13\%), lack of transportation $(13 \%)$ or distance to the facility $(12 \%)$. The median delay in arriving to a health facility after deciding to seek care was 1 hour (range: $<1-672$ ). Women who received care in primary health centres reported the longest median delay (4hours) in arriving to a health facility. The most common reasons for this delay included lack of money $(63 \%)$, lack of transportation $(24 \%)$ or distance to facility $(16 \%)$. All women attending primary health centres reported being delayed in arriving at the health centre due to a lack of money. The median delay in being attended to after arriving at a health facility was 0.5 hours (range: $<1-504$ ), generally due to non-availability of a nurse or doctor (37\%) especially in the central/provincial and district hospitals $(37 \%$ and $41 \%$, respectively). The longest overall delay (median 11 hours, range: $<1-840$ hours) occurred between being attended to and receiving complete treatment, with the longest delays in district hospitals (median 17 hours) and the shortest delays in primary health centres (median 1 hour). Nearly half (49\%) sought care elsewhere before arriving at the current facility, with the majority of these women seeking but not receiving complete care from primary health centres $(61 \%)$. Among those reporting lost income, the average loss (excluding costs of treatment or travel) was US $\$ 90.82$. This average was higher in private and NGO facilities (US\$280.27) and lowest in primary health centres (US\$41). Average lost income was higher for urban (US\$104.04) versus rural women (US\$76.71). 
Table 1 Experiences related to seeking postabortion care, Prospective Morbidity Survey

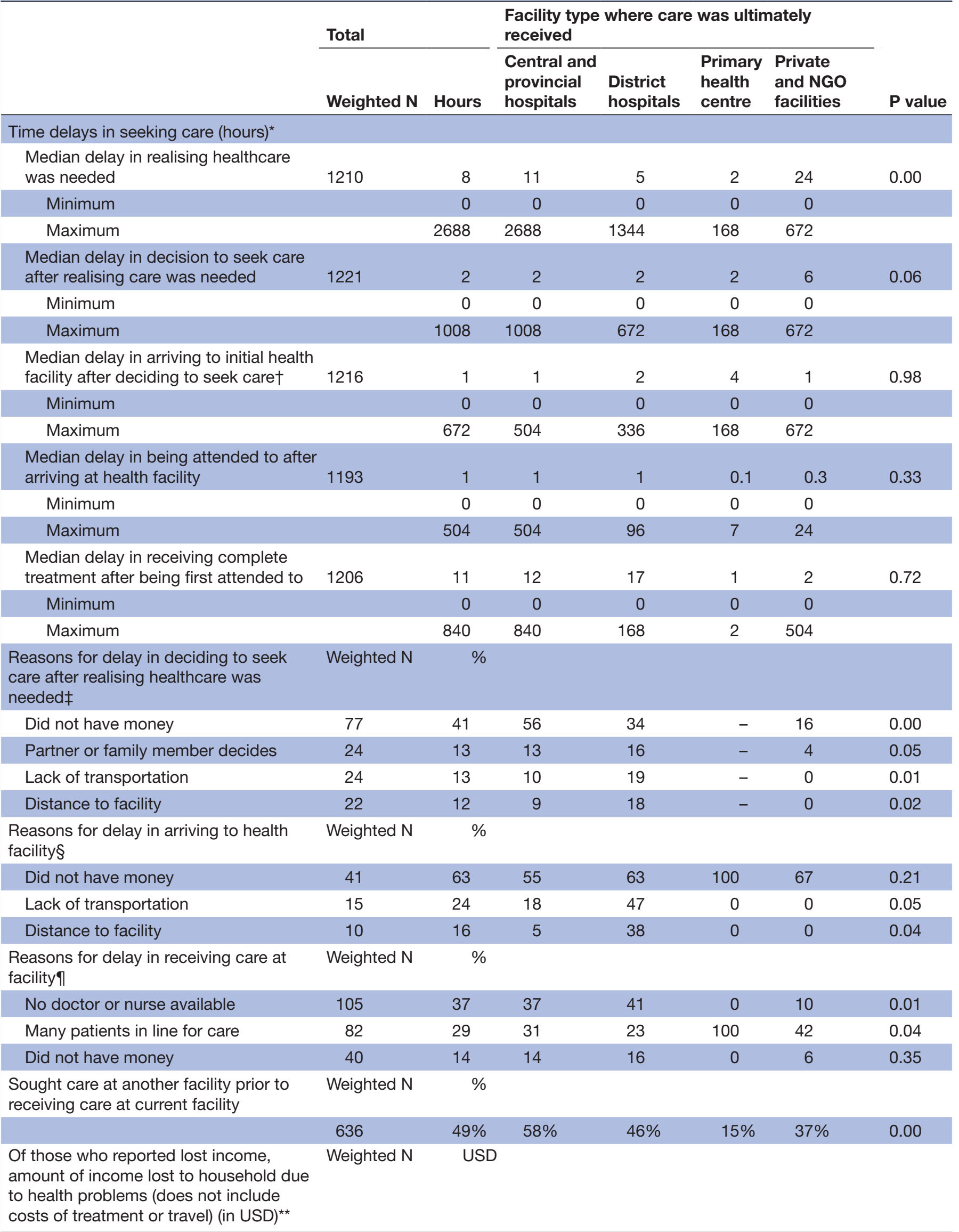




\begin{tabular}{|c|c|c|c|c|c|c|c|}
\hline & \multicolumn{2}{|l|}{ Total } & \multicolumn{4}{|c|}{$\begin{array}{l}\text { Facility type where care was ultimately } \\
\text { received }\end{array}$} & \multirow[b]{2}{*}{$P$ value } \\
\hline & Weighted N & Hours & $\begin{array}{l}\text { Central and } \\
\text { provincial } \\
\text { hospitals }\end{array}$ & $\begin{array}{l}\text { District } \\
\text { hospitals }\end{array}$ & $\begin{array}{l}\text { Primary } \\
\text { health } \\
\text { centre }\end{array}$ & $\begin{array}{l}\text { Private } \\
\text { and NGO } \\
\text { facilities }\end{array}$ & \\
\hline $\begin{array}{l}\text { Average loss of income for all } \\
\text { respondents }\end{array}$ & 320 & 90.82 & 60.16 & 94.54 & 41.00 & 280.27 & 0.06 \\
\hline $\begin{array}{l}\text { Average loss of income for rural } \\
\text { respondents }\end{array}$ & 155 & 76.71 & 47.23 & 93.16 & 41.00 & 13.12 & 0.10 \\
\hline
\end{tabular}

*These are self-reported time of delays from respondents. Two respondents had total delays greater than their estimated gestational age, and therefore were set to missing.

†This question asks for their initial visit to a health facility, not necessarily the facility where they were interviewed/received treatment. It can be interpreted as time from decision to seek care to access to healthcare system.

$\ddagger$ Out of 186 respondents. These are multiple response questions so they will not add up to 100 and the table does not present all responses. There was no data for individuals who sought care at primary health centres regarding reasons for delay in deciding to seek care after realising healthcare was needed.

§Out of 65 respondents. These are multiple response questions so they will not add up to 100 and the table does not present all responses. १Out of 120 respondents who said it took longer than a reasonable time to be attended to at facility. These are multiple response questions so they will not add up to 100 and the table does not present all responses.

${ }^{\star \star} 75 \%$ of respondents did not report a loss of income and are therefore not included in this total. If these respondents are imputed as US $\$ 0$ for loss of income, the overall average loss of income is US\$22.59.

NGO, non-governmental organisation.

In multivariate analysis, rural women had $122 \%$ higher odds (adjusted OR (adjOR) 2.22, 95\% CI1.70 to 2.91) of severe morbidity (vs low or moderate morbidity), or of moderate/severe morbidity (vs low morbidity), holding other factors in the model constant (table 2). In other words, a rural woman had over two times the odds of increasingly severe morbidity from complications of abortion versus a similar urban woman. Women older than 30 were significantly less likely ( $27 \%$ lower odds) than women aged 15-19 to have increasingly severe morbidity (adjOR $0.73,95 \%$ CI 0.55 to 0.98 ). Women not in union had $63 \%$ higher odds of increasingly severe morbidity compared with women in union (adjOR 1.63, 95\% CI 1.29 to 2.04$)$. University education was protective, conferring $54 \%$ lower odds of increasingly severe morbidity as compared with having no schooling or any primary education (adjOR 0.45 , 95\% CI 0.31 to 0.65 ). Having children increased the odds of experiencing increasingly severe morbidity by $68 \%$ (1-2 children adjOR 1.68, 95\% CI 1.33 to 2.13 ; $3+$ children adjOR $1.68,95 \%$ CI 1.13 to 2.49 ). Women in their second trimester of pregnancy had $31 \%$ higher odds of increasingly severe morbidity compared with women in their first trimester (adjOR 1.31, 95\% CI 1.01 to 1.71$)$.

$\mathrm{D} \& \mathrm{C} /$ dilatation and evacuation (D\&E) was the most common PAC procedure $(75 \%)$, except in primary health centres (which do not have the capacity to provide this service) (table 3). Only $11 \%$ of clients had medical evacuation using misoprostol, although this was $100 \%$ among clients in primary health centres. Doctors performed the majority of procedures $(91 \%)$ and most participants received antibiotics $(97 \%)$, pain medication
(78\%) and intravenous (IV) fluids (67\%). While 92\% of patients were counselled about contraception at discharge, providers reported that $43 \%$ of participants received modern contraception on discharge, with larger proportions receiving methods in primary health centres and private or NGO facilities (61\% in each), and smaller proportions receiving methods in central and provincial hospitals $(26 \%)$.

\section{DISCUSSION}

\section{Main findings}

About $40 \%$ of Zimbabwean women experiencing abortion complications are classified as having moderate or more severe complications. The proportion with severe or near-miss morbidity (21\%) is similar to recent studies done in Malawi $(21 \%)^{27}$ and in Kenya $(37 \%) .{ }^{34}$ However, proportions of severe cases in those studies were likely overestimated with the older criteria, and therefore the proportion of severe/near-miss cases in Zimbabwe is high in comparison. We identified several characteristics associated with a greater likelihood of increasingly severe abortion complications, including being young, rural, not in union, less educated, having children or at a later gestational age. Our findings are similar to those from a study in Malawi, which also reported greater risk of abortion-related morbidity among rural women and those not in union. ${ }^{27}$ In Zimbabwe, PAC is not offered in most primary health centres, which are more accessible to rural women than higher level facilities. Expanding provision of comprehensive PAC services in rural areas, especially ensuring access for adolescents, ${ }^{9}$ may help address 
Table 2 Crude and adjusted ORs* (and 95\% Cls) for the relationship between sociodemographic or abortion-related characteristics and severity of abortion complications, among women receiving postabortion care, Prospective Morbidity Survey

\begin{tabular}{|c|c|c|c|c|}
\hline Characteristic & $\begin{array}{l}\text { Crude OR } \\
(95 \% \mathrm{Cl})\end{array}$ & $P$ value & $\begin{array}{l}\text { Adjusted OR† } \\
(95 \% \mathrm{Cl})\end{array}$ & $P$ value \\
\hline \multicolumn{5}{|l|}{ Residence } \\
\hline Urban & 1.00 (reference) & & 1.00 (reference) & \\
\hline Rural & 2.33 (1.82 to 3.00$)$ & 0.00 & 2.22 (1.70 to 2.91$)$ & 0.00 \\
\hline \multicolumn{5}{|l|}{ Age } \\
\hline $15-19$ & 1.00 (reference) & & 1.00 (reference) & \\
\hline $20-29$ & 0.92 (0.69 to 1.22$)$ & 0.55 & 0.93 (0.73 to 1.18$)$ & 0.52 \\
\hline $30+$ & 0.72 (0.56 to 0.94$)$ & 0.01 & 0.73 (0.55 to 0.98$)$ & 0.04 \\
\hline \multicolumn{5}{|l|}{ Marital status $\ddagger$} \\
\hline In union & 1.00 (reference) & & 1.00 (reference) & \\
\hline Not in union & 1.30 (1.03 to 1.64$)$ & 0.03 & 1.63 (1.29 to 2.04$)$ & 0.00 \\
\hline \multicolumn{5}{|l|}{ Educational level } \\
\hline None or any primary & 1.00 (reference) & & 1.00 (reference) & \\
\hline Any secondary schooling & 0.67 (0.51 to 0.88$)$ & 0.01 & $0.94(0.72$ to 1.24$)$ & 0.67 \\
\hline University or more & 0.25 (0.18 to 0.36$)$ & 0.00 & 0.45 (0.31 to 0.65$)$ & 0.00 \\
\hline \multicolumn{5}{|l|}{ No of living children } \\
\hline None & 1.00 (reference) & & 1.00 (reference) & \\
\hline $1-2$ & 1.26 (1.01 to 1.57$)$ & 0.04 & 1.68 (1.33 to 2.13$)$ & 0.00 \\
\hline $3+$ & 1.37 (1.04 to 1.80$)$ & 0.03 & 1.68 (1.13 to 2.49$)$ & 0.01 \\
\hline \multicolumn{5}{|l|}{ Estimated gestational age } \\
\hline First trimester & 1.00 (reference) & & 1.00 (reference) & \\
\hline Second trimester & $1.42(1.08$ to 1.87$)$ & 0.01 & $1.31(1.01$ to 1.71$)$ & 0.04 \\
\hline \multicolumn{5}{|c|}{ Facility where postabortion care was received } \\
\hline Primary health centre & 1.00 (reference) & & - & \\
\hline District hospitals & $1.50(0.45$ to 5.00$)$ & 0.50 & - & - \\
\hline Provincial and Central hospitals & $0.72(0.22$ to 2.30$)$ & 0.57 & - & - \\
\hline Private and NGO facilities & $0.49(0.15$ to 1.61$)$ & 0.24 & - & - \\
\hline \multicolumn{5}{|l|}{ Relative wealth quintile } \\
\hline Poorest & 1.00 (reference) & & 1.00 (reference) & \\
\hline Poor & 1.17 (0.86 to 1.59$)$ & 0.32 & 1.09 (0.83 to 1.43$)$ & 0.51 \\
\hline Medium & $0.86(0.60$ to 1.24$)$ & 0.42 & 0.84 (0.59 to 1.20$)$ & 0.32 \\
\hline Wealthy & 0.90 (0.67 to 1.21$)$ & 0.48 & 0.88 (0.65 to 1.20$)$ & 0.42 \\
\hline Wealthiest & 0.84 (0.64 to 1.09$)$ & 0.19 & 0.80 (0.63 to 1.02$)$ & 0.08 \\
\hline \multicolumn{5}{|c|}{$\begin{array}{l}\text { Time between deciding to seek care and arrival } \\
\text { at a facility§ }\end{array}$} \\
\hline No delay (wait <2 hours) & 1.00 (reference) & & - & \\
\hline Less than a day & 1.28 (1.03 to 1.60$)$ & 0.03 & - & - \\
\hline $1+$ days & 0.90 (0.57 to 1.43$)$ & 0.66 & - & - \\
\hline
\end{tabular}

*Model is an ordinal logistic regression where the outcome is three levels: mild complications; moderate complications; severe complications or near miss or death.

†Bivariate and multivariate models are restricted to cases with no item non-response for any of the variables in the table. The weighted $\mathrm{N}$ for the multivariate model is 1232 .

‡ln union indicates currently married or living together; not in union indicates never married, with partner and not living together, or separated/ divorced/widowed.

§Refers to the initial facility the respondent went to, which might not be the same facility where the respondent ultimately received care.

-Not included in final regression.

NGO, non-governmental organisation. 
Table 3 Treatment and services received by postabortion care clients, Prospective Morbidity Survey

\begin{tabular}{|c|c|c|c|c|c|c|}
\hline Total & & Facility type & & & & \\
\hline Weighted N & $\%$ & $\begin{array}{l}\text { Central and } \\
\text { provincial } \\
\text { hospitals (\%) }\end{array}$ & $\begin{array}{l}\text { District } \\
\text { hospitals (\%) }\end{array}$ & $\begin{array}{l}\text { Primary health } \\
\text { centre }(\%)\end{array}$ & $\begin{array}{l}\text { Private } \\
\text { and NGO } \\
\text { facilities (\%) }\end{array}$ & $P$ value \\
\hline 577 & 46 & 43 & 61 & 0 & 20 & 0.00 \\
\hline
\end{tabular}

Patient stayed in facility $>24$ hours $577 \quad 46 \quad 43$

Main procedure used in

management of patient's

condition*

0.00

\begin{tabular}{|c|c|c|c|c|c|c|c|}
\hline \\
\hline D\&C/D\&E† & 760 & 75 & 74 & 78 & 0 & 67 & \\
\hline $\begin{array}{l}\text { Manual/electric vacuum } \\
\text { aspiration }\end{array}$ & 125 & 12 & 17 & 6 & 0 & 14 & \\
\hline Misoprostol & 113 & 11 & 9 & 12 & 100 & 17 & \\
\hline Oxytocin & 21 & 2 & 0 & 4 & 0 & 2 & \\
\hline \multicolumn{7}{|c|}{ Procedure performed primarily by: } & 0.00 \\
\hline Doctorł & 960 & 91 & 99 & 83 & 0 & 87 & \\
\hline $\begin{array}{l}\text { Nurse/midwife/clinical } \\
\text { officer }\end{array}$ & 93 & 9 & 1 & 17 & 100 & 13 & \\
\hline Received intravenous fluids & 848 & 67 & 70 & 71 & 36 & 46 & 0.01 \\
\hline Antibiotics provided & 1232 & 97 & 96 & 99 & 85 & 98 & 0.01 \\
\hline Pain medication provided & 960 & 78 & 79 & 75 & 64 & 91 & 0.08 \\
\hline \multicolumn{8}{|l|}{ Contraceptive services } \\
\hline \multicolumn{7}{|l|}{$\begin{array}{l}\text { Patient counselled on } \\
\text { contraception at discharge }\end{array}$} & 0.00 \\
\hline Yes & 1154 & 92 & 88 & 96 & 100 & 91 & \\
\hline No & 76 & 6 & 10 & 2 & 0 & 8 & \\
\hline Not discharged yet & 25 & 2 & 2 & 2 & 0 & 1 & \\
\hline \multicolumn{7}{|l|}{$\begin{array}{l}\text { Patient received modern } \\
\text { contraception at discharge§ }\end{array}$} & 0.01 \\
\hline Yes & 535 & 43 & 26 & 55 & 61 & 61 & \\
\hline No & 650 & 52 & 67 & 40 & 39 & 37 & \\
\hline Don't know & 69 & 6 & 7 & 5 & 0 & 2 & \\
\hline
\end{tabular}

${ }^{*}$ Out of women who obtained procedures (weighted $n=1018$ ).

†D\&C/D\&E includes: dilatation and curettage (D\&C) (12\%), evacuation by sharp curettage (50.5\%), digital evacuation (1.5\%) and forceps evacuation (10.4\%).

‡Includes Obstetrician and Gynaecologist (34\%) and medical officers/GPs/senior resident medical officers (57\%).

$\S$ The definition of 'modern' contraception was not included in the question; so it is possible that providers may have interpreted this term slightly variably.

D\&C, Dilation and curettage, D\&E, Dilatation and evacuation; GPs, general practitioners; NGO, non-governmental organisation.

this inequity. Empowerment of young women, including through educational opportunities and health literacy, may play a role in maximising health and reducing unintended pregnancy and recourse to unsafe abortion. ${ }^{35}$

Financial constraints represented the most common reason for delays in care seeking. Despite the Ministry of Health and Child Care national policy that PAC should be free in public facilities; women still pay for transport, additional service fees and other expenses. The costs of seeking PAC may be inaccessible for many, and women in our sample (ie, those who successfully sought and received PAC) were wealthier than the national wealth distribution in Zimbabwe, suggesting potential selection of wealthier individuals into receipt of these services. Similarly, facility access for deliveries in Zimbabwe also increases progressively by wealth ( $61 \%$ for women in the lowest quintile; $95 \%$ for women in the highest). ${ }^{9}$ As lower income women are more likely to have less safe abortions than richer women, enhancing accessibility and affordability of PAC services for poorer women is essential to decrease maternal mortality. Women seeking care in primary health centres reported the longest median delay in arriving at a facility; these facilities tend to be more remote, particularly in rural areas, and most likely require that women have funding for and access to transportation. The median delay to receiving complete treatment ( 11 hours) could be considerably reduced if medical evacuation with misoprostol is adopted in all facilities. Surgical evacuation of the uterus is usually done at 
set times to allow organisation of operating theatres, while medical evacuation can be offered immediately on diagnosis of incomplete abortion. One-hird of clients first sought care at primary health centres but needed to go to higher level facilities to receive PAC; the lack of PAC capacity at many primary health centres further delays management and potentially increases the severity of complications, including the possibility of death. Enabling primary health centres to provide PAC using misoprostol or MVA would reduce costs and improve accessibility, decongest higher level facilities and presumably reduce maternal mortality.

A Zimbabwean pilot study found that using misoprostol for PAC reduced referral rates in primary health centres (from $98 \%$ to $10 \%$ ) and rural/mission hospitals (from $48 \%$ to $3 \%$ ), while maintaining $96 \%$ efficacy. ${ }^{36}$ However, in our study, most PAC cases were managed with D\&C/D\&E and few were managed with MVA/electrical vacuum aspiration (12\%) or misoprostol (11\%). Using medical evacuation with misoprostol is considerably less expensive than surgical evacuations while MVA is safer and results in less perioperative blood loss. ${ }^{37}$ Zimbabwe lags behind other countries like Malawi ${ }^{27}$ and Kenya $^{34}$ in adopting MVA. Furthermore, although most clients in our study were managed by medical doctors, training midwives and nurses to use misoprostol and MVA, when appropriate and as allowed under current law, will improve PAC availability, shorten delays and consequently reduce severity, particularly in settings without doctors, like primary health centres. Receipt of IV fluids by $67 \%$ of patients suggests potential overuse, as this is generally only necessary for women with moderate or greater severity. Conversely, we observed a potential underuse of analgesics; all patients receiving PAC should receive this, ${ }^{37}$ but only $78 \%$ did. We recommend in-service training of clinicians in the national PAC guidelines and regular audits to check whether clinicians are following the guidelines, or are experiencing stock-outs which prevent them from doing so.

\section{Strengths}

Our study was nationally representative, involving all provinces in Zimbabwe and sampling all central and provincial hospitals. Prospective data collection in facilities avoided concerns encountered in retrospective studies assessing abortion-related morbidity due to missing patient records. Using a patient interview, provider interview and case notes improved data accuracy. We achieved a high response rate in sampled facilities (95\%). The revised morbidity criteria reduced potential overestimation of severity by removing unreliable stand-alone criteria such as fever and tachycardia. In addition, our comparison of treatment provided to national PAC guidelines and consideration of women's delays to care are relevant to policies to improve the clinical management and quality of PAC.

\section{Limitations}

Our study has several limitations. First, we were unable to distinguish between induced and spontaneous abortions, and as noted above, complications from induced abortions may be more severe than those from spontaneous abortions. ${ }^{26}$ We asked women if they had done anything to interfere with the pregnancy, but acknowledgement was extremely rare $(4 \%)$, potentially owing to fear of legal repercussions. We did not consider this self-reported information to be sufficiently reliable. Second, as a facility-based study, information on women with mild complications that resolved spontaneously, severe complications leading to death outside the facility, or any other case of PAC occurring outside of a facility were not captured. Third, although we used prospective data collection, we were unable to gather information on 2 women who died and 12 women classified as near misses in tracking forms. Thus, the most severe cases may still be underestimated.

\section{Generalisability of results}

We collected data from over half of all PAC-providing facilities in Zimbabwe, including all higher level facilities, and our results are nationally representative. Regarding generalisability of our findings beyond Zimbabwe, facility-based measures of abortion morbidity are influenced both by abortion safety and women's access to treatment, which varies across contexts. Our findings on the severity of postabortion complications are likely generalisable to other countries facing similar resource constraints, and with similar levels of abortion safety. The impact of recent declines in Zimbabwe's healthcare system on abortion morbidity are difficult to quantify, but should be considered in applying these findings elsewhere. Furthermore, little is known about levels of misoprostol access for termination of pregnancy across the region, including Zimbabwe. If misoprostol use, and therefore abortion safety, is different in Zimbabwe compared with other countries, this may also limit generalisability. However, our findings on the characteristics associated with severity and the delays in access to care are likely generalisable to other countries in the region, where access to care is shaped by geography and resources. ${ }^{2734}$ In addition, Zimbabwe lags behind its regional counterparts in rolling out MVA as the standard of care for surgical evacuation of the uterus. ${ }^{2734}$

\section{CONCLUSION}

In Zimbabwe, abortion-related morbidity and concomitant mortality could be reduced by liberalising the abortion law, providing PAC in primary health centres, and training nurses to use medical evacuation with misoprostol and MVA. Regular in-service training on PAC guidelines should be done with follow-up audits to ensure compliance and availability of equipment, supplies and trained staff. Besides in-service training as a class-based approach, coaching and mentorship are necessary for performance improvement of health providers. ${ }^{38}$ Efforts are needed to reduce unintended pregnancy and unsafe abortion among those more likely to have severe abortion-related complications, including adolescents and women in rural areas, those with less education or those not in union. Further 
research should address motivations and barriers for providers to adopt evidence-based best practice for comprehensive PAC.

Acknowledgements We are grateful to our study team members, Bernard Madzima and Margaret Nyandoro at the ministry of health and child care, Marjorie Crowell and Ann Moore and at the Guttmacher Institute, and our study coordinator, Engeline Mawere and fieldwork supervisor Olga Chisango. We are also grateful to all of our data collectors, supervisors and the individuals who agreed to participate in this study. Finally, we are grateful to Nirali Chakraborty for her assistance in understanding the development of wealth indices, and to Tamara Fetters for her helpful feedback in the design stage of this project.

Contributors MGM, ES and TC were primarily responsible for conceiving of the project, and MGM, TR, ES and TC for carrying out data collection. MGM, 00 and TC were primarily responsible for conceptualising the updates to the abortion complication severity classification scheme. CBP, TR and ES were primarily responsible for cleaning and analysing the data. MGM, CBP and TR drafted the first version of the manuscript. All authors (MGM, CBP, TR, ES, 00 and TC) assisted in the writing and approved the final manuscript.

Funding This study was made possible by the Swedish international development cooperation agency and UK aid from the UK government. Additional support was provided by the Guttmacher Center for population research innovation and dissemination (NIH grant 5 R24HD074034). The findings and conclusions contained in the study are those of the authors and do not necessarily reflect the positions and policies of the donors.

Competing interests None declared.

Patient consent Obtained.

Ethics approval We obtained ethical approval from the institutional ethics board of the Guttmacher Institute (20 May 2016), the Medical Research Council of Zimbabwe (28 April 2016, approval number MRCZ/A/2061) and from the Joint Research Ethics Committee for the University of Zimbabwe, College of Health Sciences and Parirenyatwa Group of Hospitals (4 April 2016, reference number JREC/379/15).

Provenance and peer review Not commissioned; externally peer reviewed.

Data sharing statement Given the sensitive nature of the data, the dataset is not currently publically available. We are determining ethical clearance to make this data set available to other researchers. All the data have been analysed and are being presented in this article.

Open Access This is an Open Access article distributed in accordance with the Creative Commons Attribution Non Commercial (CC BY-NC 4.0) license, which permits others to distribute, remix, adapt, build upon this work non-commercially, and license their derivative works on different terms, provided the original work is properly cited and the use is non-commercial. See: http://creativecommons.org/ licenses/by-nc/4.0/

(C) Article author(s) (or their employer(s) unless otherwise stated in the text of the article) 2018. All rights reserved. No commercial use is permitted unless otherwise expressly granted.

\section{REFERENCES}

1. World Health Organization. Unsafe abortion: Global and regional estimates of the incidence of unsafe abortion and associated mortality in 2008. Sixth edn. Geneva: World Health Organization, 2011.

2. Ganatra B, Gerdts C, Rossier C, et al. Global, regional, and subregional classification of abortions by safety, 201014: estimates from a Bayesian hierarchical model. Lancet 2017;390:2372-2381.

3. Singh S, Darroch J, Ashford L. Adding it Up: The Costs and Benefits of Investing in Sexual and Reproductive Health. New York: Guttmacher Institute, 2014.

4. Global Burden of Disease Study 2015. Global burden of disease study 2015 (gbd 2015) healthcare access and quality index based on amenable mortality 1990-2015. Seattle: Institute for Health Metrics and Evaluation, 2017. http://ghdx.healthdata.org/gbd-results-tool (accessed 7 Jul 2017).

5. Zimbabwe Termination of Pregnancy Act [Chapter 15:10], 1977. http://www.parlzim.gov.zw/acts-list/termination-of-pregnancy-act$15-10$
6. Sedgh G, Bearak J, Singh S, et al. Abortion incidence between 1990 and 2014: global, regional, and subregional levels and trends. Lancet 2016;388:258-67.

7. United Nations. The Millennium Development Goals Report 2015 , 2015. http://www.un.org/millenniumgoals/2015_MDG_Report/pdf/ MDG\%202015\%20rev\%20(July\%201).pdf (accessed 16 Aug 2017).

8. WHO, UNICEF, UNFPA. Trends in maternal mortality: 1990 to 2010: WHO, UNICEF, UNFPA and the World Bank estimates. Geneva: World Health Organization, 2012.

9. Zimbabwe National Statistics Agency, ICF International. 2016. Zimbabwe Demographic and Health Survey 2015: Final Report.

10. Fawcus S, Mbizvo M, Lindmark G, et al. Unsafe abortions and unwanted pregnancies contribute to maternal mortality in Zimbabwe. S Afr Med J 1996;86:430-6.

11. Zimbabwe U, Munjanja S. Ministry of Health and Child Welfare Zimbabwe. The Zimbabwe Maternal and Perinatal Mortality Study: UNFPA, 2007.

12. Chipato T. Zimbabwe Ministry of Health and Child Care. National Guidelines for Comprehensive Abortion Care in Zimbabwe. 2nd edn, 2014.

13. Odland ML, Rasmussen $\mathrm{H}$, Jacobsen GW, et al. Decrease in use of manual vacuum aspiration in postabortion care in Malawi: a crosssectional study from three public hospitals, 2008-2012. PLoS One 2014:9:e100728.

14. Zimbabwe National Statistics Agency (ZIMSTAT). 2013. Poverty Income Consumption and Expenditure Survey 2011/12 Report. Harare: ZIMSTAT.

15. Culwell KR, Hurwitz M. Addressing barriers to safe abortion. Int $J$ Gynaecol Obstet 2013;121:S16-S19.

16. Figà-Talamanca I, Sinnathuray TA, Yusof K, et al. Illegal abortion: an attempt to assess its cost to the health services and its incidence in the community. Int J Health Serv 1986;16:375-89.

17. Fetters T. Prospective approach to measuring abortion-related morbidity: individual-level data on postabortion patients. In: Methodologies for Estimating Abortion Incidence and AbortionRelated Morbidity: A Review. New York: Guttmacher Institute, 2010:135-46.

18. Gebreselassie H, Gallo MF, Monyo A, et al. The magnitude of abortion complications in Kenya. BJOG 2005;112:1229-35.

19. Levandowski BA, Pearson E, Lunguzi J, et al. Reproductive health characteristics of young Malawian women seeking post-abortion care. Afr J Reprod Health 2012;16:253-62.

20. Jewkes R, Brown H, Dickson-Tetteh K, et al. Prevalence of morbidity associated with abortion before and after legalisation in South Africa. BMJ 2002;324:1252-3.

21. Rees H, Katzenellenbogen J, Shabodien R, et al. The epidemiology of incomplete abortion in South Africa. National Incomplete Abortion Reference Group. South Afr Med J Suid-Afr Tydskr Vir Geneeskd 1997;87:432-7.

22. Gebreselassie H, Fetters T, Singh S, et al. Caring for women with abortion complications in Ethiopia: national estimates and future implications. Int Perspect Sex Reprod Health 2010;36:006-15.

23. Chae S, Kayembe P, Philbin J, et al. The incidence of induced abortion in Kinshasa, Democratic Republic of Congo, 2016. PLoS One;12:e0184389.

24. Sully $\mathrm{E}$, et al. The incidence of induced abortion in Zimbabwe (TK need to update). In press.

25. Wekwete N, Rusakaniko S, Zimbizi G. UNFPA Zimbabwe National Adolescent Fertility Study. Harare: Ministry of Health and Child Care, 2016.

26. Adler AJ, Filippi V, Thomas SL, et al. Incidence of severe acute maternal morbidity associated with abortion: a systematic review. Trop Med Int Health 2012;17:177-90.

27. Kalilani-Phiri L, Gebreselassie H, Levandowski BA, et al. The severity of abortion complications in Malawi. International Journal of Gynecology \& Obstetrics 2015;128:160-4.

28. World Health Organization, Department of Reproductive Health and Research, others. Evaluating the quality of care for severe pregnancy complications: the WHO near-miss approach for maternal health, 2011.

29. Nelissen EJ, Mduma E, Ersdal HL, et al. Maternal near miss and mortality in a rural referral hospital in northern Tanzania: a crosssectional study. BMC Pregnancy Childbirth 2013;13:141.

30. Owolabi OO, Cresswell JA, Vwalika B, et al. Incidence of abortionrelated near-miss complications in Zambia: cross-sectional study in Central, Copperbelt and Lusaka Provinces. Contraception 2017;95:167-74.

31. Filippi V, Ganaba R, Baggaley RF, et al. Health of women after severe obstetric complications in Burkina Faso: a longitudinal study. Lancet 2007;370:1329-37. 
32. Houweling TA, Kunst AE, Mackenbach JP. Measuring health inequality among children in developing countries: does the choice of the indicator of economic status matter? Int J Equity Health 2003;2:8.

33. Long JS, Freese J. Regression Models for Categorical Dependent Variables Using Stata. 2nd edn: College Station, Tex: Stata Press, 2005.

34. Ziraba AK, Izugbara C, Levandowski BA, et al. Unsafe abortion in Kenya: a cross-sectional study of abortion complication severity and associated factors. BMC Pregnancy Childbirth 2015;15:34.

35. Duflo E, Dupas P, Kremer M. Education, HIV, and Early Fertility: Experimental Evidence from Kenya. Am Econ Rev 2015;105:2757-97.
36. Zimbabwe Ministry of Health and Child Care, Venture Strategies Innovations. Expanding Access to Postabortion Care in Zimbabwe through Integration of Misoprostol. Harare: Zimbabwe Ministry of Health and Child Care, 2013.

37. Tunçalp O, Gülmezoglu AM, Souza JP. Surgical procedures for evacuating incomplete miscarriage. Cochrane Database Syst Rev 2010.doi: 10.1002/14651858.CD001993.pub2. [Epub ahead of print 8 sep 2010].

38. Bluestone $\mathrm{J}$, Johnson $\mathrm{P}$, Fullerton $\mathrm{J}$, et al. Effective in-service training design and delivery: evidence from an integrative literature review. Hum Resour Health 2013;11:51. 